\title{
EVALUATION OF SERVICE LIFE OF CONCRETE PAVEMENT BY MONTE CARLO SIMULATION
}

\author{
By J. Rafael MONTAÑN M.*, Masashi KOYANAGAWA** and Tadashi FUKUDA***
}

\begin{abstract}
Service life of concrete pavement is influenced by uncertainty factors inherent in pavement conditions. This study describes a method of Monte Carlo simulation to evaluate the service life of concrete pavement taken into account these uncertainty factors. Results of the simulation illustrated in this study showed that the probability density function of service life can be expressed by a Beta distribution and the reliability of concrete pavement can be evaluated by this simulation method.

Keywords : concrete pavement, service life, Monte Carlo simulation
\end{abstract}

\section{INTRODUCTION}

In recent years, researchers in the United States intended to apply stochastic reliability theory for uncertainty factors to pavement design. Thus this reliability theory has been introduced into the pavement design of the AASHTO Guide ${ }^{1)}$ revised in 1986.

The reliability concept applied into pavement design is defined as the survival probability that the pavement structure will perform its intended functions under environmental conditions within its design life period.

In conventional concrete pavement design, the service life has been calculated deterministically for design conditions. Darter ${ }^{2)}, \mathrm{Kher}^{3)}$ and $\mathrm{Witczak}^{4)}$ investigated uncertainty factors within the design variables and consequently these studies became a background of the revised AASHTO Guide.

In Japan, the method in the appendix of the Manual for Design and Construction of Concrete Pavement ${ }^{5)}$ has been used as standard. This method is a mechanical technique based on stress analysis of pavement structure, whereas in contrast, the AASHTO Guide is an experimental design based on the AASHO Road Test. Consequently, in order to introduce the reliability theory into the pavement design in Japan, it is necessary to develop a method different from those established in the United States.

Generally, variations in an estimation of service life of concrete pavement can be attributed to external conditions (i.e. traffic and thermal effects) and internal conditions (i.e. structure and material conditions). Since the purpose of this investigation is to study the variations that exist in the deterministic design, the authors adopted the Monte Carlo simulation method in order to evaluate stochastically the

\footnotetext{
* Student member of JSCE, Graduate student, Tohoku University (Sendai 980 Japan).

** Member of JSCE, M. Eng., Research Associate, Akita College of Technology (Akita 011 Japan).

*** Member of JSCE, Dr. Eng., Professor, Tohoku University (Sendai 980 Japan).
} 
reliability of concrete pavement. Subsequently the simulation was carried out by generating random numbers for the external and the internal conditions.

\section{SIMULATION}

The simulation was carried out fundamentally following the procedure in the appendix of the Manual with some modifications based on the study by the authors ${ }^{6}$. The design of the Manual considers that concrete slab failure occurs at its longitudinal joint edge. However, according to this study, slab failure is greatly influenced by its width and traffic volume. Especially in the case of slab width $3.00-4.00 \mathrm{~m}$ and high volume of commercial vehicles, slab failure occurs at its transverse joint edge. Consequently calculation of fatigue damage in this study is based on cracking at its transverse joint edge.

(1) Traffic effects

Density distribution of wheel load was obtained from the surveying results for D-traffic by the Ministry of Construction (Table 1) ${ }^{7}$, and the density distribution of wheel passing position was obtained from the surveying result by the authors $(\text { Table } 2)^{8)}$.

The cumulative distribution function $(\mathrm{CDF})$ for the right wheel passing position is approximated as follows:

$$
F_{x}(x)=0.48 \int_{5}^{x} \exp \left[-0.5\left(\frac{x-7.73}{0.83}\right)^{2}\right] d x
$$

where

$x$ : right wheel passing position measured from left

Table 1 Cumulative Frequency of Wheel Load.

\begin{tabular}{|c|c|c|}
\hline $\begin{array}{c}\text { Wheel } \\
\text { Load } \\
(t)\end{array}$ & $\begin{array}{c}\text { Input Data of } \\
\text { Cumulative Freq. } \\
(\%)\end{array}$ & $\begin{array}{c}\text { Output Data of } \\
\text { Cumulative Freq. } \\
(\%)\end{array}$ \\
\hline 1 & 60.1500 & 60.1499 \\
\hline 2 & 73.2300 & 73.2297 \\
\hline 3 & 84.4200 & 84.4197 \\
\hline 4 & 91.5800 & 91.5796 \\
\hline 5 & 95.2200 & 95.2197 \\
\hline 6 & 97.4800 & 97.4799 \\
\hline 7 & 98.8500 & 98.8501 \\
\hline 8 & 99.4900 & 99.4801 \\
\hline 9 & 99.8000 & 99.7900 \\
\hline 10 & 99.9330 & 99.9200 \\
\hline 12 & 99.9970 & 99.9900 \\
\hline 14 & 100.0000 & 100.0000 \\
\hline
\end{tabular}

slab edge, in the case of the slab being divided into ten equal units $(5 \leqq x \leqq 10)$.

Flexural stress is calculated at the most frequent passing position. This flexural stress decreases when wheel passes away from the position. The decreasing rate $r_{\sigma}$ is expressed on the basis of the experimental result by Iwama $^{9)}$ as follows :

$$
r_{\sigma}=\exp \left[-0.32(x-7.73)^{2}\right]
$$

\section{( 2 ) Thermal effects}

The distribution of temperature difference between top and bottom of concrete slab is given in the Manual. The distribution is approximately expressed by the following CDF :

In the case of negative temperature differences $\left(t \leqq 10^{\circ} \mathrm{C}\right)$

$F_{T}(t)=3.25 \times 10^{-7} \int_{0}^{t}\left[t^{0.76}(10-t)^{6.32}\right] d t$

In the case of positive temperature differences $\left(t \leqq 22^{\circ} \mathrm{C}\right)$

$F_{T}(t)=1.45 \times 10^{-6} \int_{0}^{t}\left[t^{0.06}(22-t)^{3.85}\right] d t$

Table 2 Cumulative Frequency of Wheel Passing Positions (WPP) and Temperature

\begin{tabular}{|c|c|c|c|c|c|c|}
\hline \multicolumn{4}{|c|}{ Input Data } & \multicolumn{3}{|c|}{ Output Data } \\
\hline \multirow{2}{*}{$\begin{array}{l}\text { Cumu. } \\
\text { Freq. } \\
\%\end{array}$} & \multirow{2}{*}{$\begin{array}{l}\text { WPP 8) } \\
\times \\
\end{array}$} & \multicolumn{2}{|c|}{$\mathrm{TO}^{51}\left({ }^{\circ} \mathrm{C}\right)$} & \multirow{2}{*}{$\begin{array}{l}\text { Cumu. } \\
\text { Freq. of } \\
\text { WPP (\%) }\end{array}$} & \multicolumn{2}{|c|}{ Cumu. Freq. of To (\%) } \\
\hline & & Positive & Negative & & Positive & Negative \\
\hline 10 & 6.67 & 0.56 & 0.05 & 10.05 & 10.0008 & 10.0000 \\
\hline 20 & 7.04 & 1.12 & 0.52 & 20.10 & 20.0010 & 20.0006 \\
\hline 30 & 7.30 & 1.72 & 0.83 & 30.15 & 30.0004 & 30.0004 \\
\hline 40 & 7.52 & 2.39 & 1.12 & 40.20 & 40.0006 & 40.0010 \\
\hline 50 & 7.73 & 3.14 & 1.41 & 50.25 & 50.0002 & 50.0006 \\
\hline 60 & 7.94 & 4.02 & 1.71 & 60.30 & 60.0004 & 60.0000 \\
\hline 70 & 8.16 & 5.07 & 2.05 & 70.35 & 70.0000 & 69.9998 \\
\hline 80 & 8.43 & 6.44 & 2.44 & 80.40 & 79.9998 & 79.9996 \\
\hline 90 & 8.79 & 8.50 & 2.95 & 90.45 & 89.9998 & 89.9998 \\
\hline 100 & 10.00 & 15.43 & 3.70 & 100.00 & 100.0000 & 100.0000 \\
\hline
\end{tabular}
Differences (TD). 
where

$t:$ absolute value of temperature difference $\left({ }^{\circ} \mathrm{C}\right)$.

\section{(3) Fatigue strength}

Fatigue analysis is based on the experimental result of the study by the authors ${ }^{10)}$. According to the result, cycles to failure for a respective stress level $S$ are log-normally distributed with a mean $\lambda$ and a standard deviation $\zeta$. The relationship between $\lambda$ and $S$ is expressed as follows:

$$
S=1.0867-0.0236 \lambda
$$

where

$S:$ stress level representing the ratio of repeating flexural stress to its static flexural strength.

Furthermore, stress level $S$ can also be expressed as a function of its respective minimum cycles to failure $N_{\min }$.

$$
S=1.1014-0.0402 \ln \left(N_{\text {min }}\right)
$$

Then, by applying equations ( 5 ) and (6), their respective values $\lambda$ and $N_{\min }$ for stress levels that have not tested can be estimated. Table 3 shows approximated values $\lambda, \zeta$ and $N_{\min }$ for their respective stress levels. Subsequently in the simulation, the log-normal distributions in Table 3 gives the number of cycles to failure for their respective stress levels.

\section{(4) Filter}

A simulation operation was carried out for annual traffic volume in consideration of periodic thermal condition, and this operation was repeated 200 times. Hence, the whole simulation needs a considerable time of computer calculation. Then, the simulation applies a filter that takes account of stress levels greater or equal to 0.60 . The stress levels that not taken into account are negligible in fatigue analysis.

\section{(5) Random numbers}

The multiplicative congruential method ${ }^{11)}$ was applied to generate uniformly distributed random numbers between 0 and 1 by the following recursive calculation of the residues of modulus $m$ :

$$
x_{i+1}=a x_{i}(\bmod m)
$$

where

$a, m:$ nonnegative integers

$x_{i+1}:(i+1)$ th generated random number.

Normalizing these numbers by the modulus $m$ :

$u_{i}=\frac{x_{i}}{m}$

$u_{i}(i=1,2, \cdots, n)$ constitutes a set of random numbers uniformly distributed between 0 and 1 . Since these random numbers are cyclic in a period less than $m$, simulation requires a large $m$ value.

On the other hand, the correlation coefficient $\rho$ between $x_{i}$ and $x_{i+1}$ is expressed as follows:

$\rho=\frac{1}{a} \pm \frac{a}{m}$

Consequently, in order to have non-repeated random numbers in the simulation, modulus $m$ is adopted as follows :

$$
m=V_{d} T I=929071000=2^{29.79} \simeq 2^{30}
$$

where

$$
V_{d}: \text { daily traffic volume of } \mathrm{D} \text {-traffic }(=12727 \text { vehicles) }
$$

$T: 365$ days

$I$ : operation repetitions of simulation $(=200)$. 
In this study $a=5^{11}$ was adopted ${ }^{111}$. Then the correlation coefficient between $x_{i}$ and $x_{i+1}$ is given by Eq. ( 9 ) as $\rho \simeq 0.0455$, which means the random numbers are statistically independent.

\section{(6) Process of simulation}

The simulation procedure was proceeded as the flow chart shown in Fig. 1. An example of the analysis by this simulation process is described for the following design conditions :

Modulus of elasticity of concrete $\cdots E=350000 \mathrm{~kg} / \mathrm{cm}^{2}$

Poisson's ratio of concrete $\cdots \cdots \cdots \cdots, \mu, \mu=0.22$

Flexural strength of concrete $\cdots \cdots \cdots \cdot \sigma=45.0 \mathrm{~kg} / \mathrm{cm}^{2}$

Coefficient of thermal expansion of

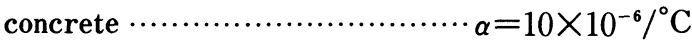

Concrete slab thickness $\cdots \cdots \cdots \cdots \cdots \cdot H=25.00 \mathrm{~cm}$

Modulus of subbase reaction …... $K_{75}=5.0 \mathrm{~kg} / \mathrm{cm}^{3}$

Design life …..........................20 years

Based on the above design conditions, a combined flexural stress matrix (CFSM) for wheel load, wheel passing position and temperature differences is formulated. Then, filter is applied to the CFSM, and stress levels less than 0.60 are rejected.

Next, a set of random numbers are generated for the random variables $R_{1}, R_{2}, R_{3}, R_{4}$ and $R_{5}$. The function of

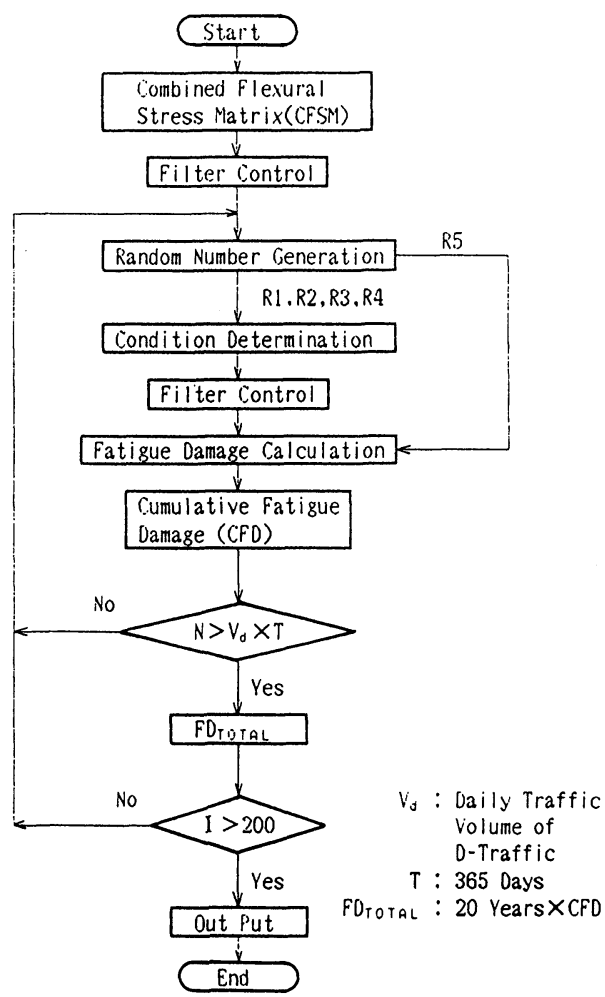

Fig. 1 Flow Chart of Simulation Process. each random variable in the simulation process is as follows:

$R_{1}$ : to determine whether the temperature difference is positive or negative

$R_{2}:$ to determine the temperature difference

$R_{3}:$ to determine the wheel load

$R_{4}:$ to determine the wheel passing position

$R_{5}:$ to determine the number of cycles to failure

The random variables $R_{1} \sim R_{4}$ determine a respective combined stress by the CFSM, hence stress level is determined. Here, filter is applied again and stress level less than 0.60 is rejected.

After stress level is determined, the number of cycles to failure is obtained by the application of random variable $R_{5}$ to the relationship between stress level and cycles to failure given in Table 3. Finally fatigue damage of concrete slab is determined.

Since thermal effect has a return period of one year $(T=365$ days), the simulation operation was carried out for one year of daily traffic volume of D-traffic $\left(V_{d}\right)$. Hence each operation consists of $N=V_{d}$ $\times T$ iterations. Therefore, total fatigue damage of one simulation operation is expressed by the cumulative fatigue damage after $N$ iterations. Furthermore, fatigue damage of concrete slab for 20 years of design life was assumed to be equal to 20 times the total fatigue damage attained in one operation. The simulation operation is repeated 200 times.

\section{SERVICE LIFE EVALUATION}

\section{(1) Data verification}

Firstly, in order to verify the input data, a comparison was carried out between the input and the output random variables for each CDF. Comparison for the distributions of wheel load is shown in Table 1, and comparisons for the distributions of wheel passing position and temperature difference are shown in 
Table 2. The result of the comparison shows good agreement between the input and the output variables, and consequently it can be considered that the simulation performed satisfactorily.

\section{(2) Fatigue damage distribution}

In order to examine the influence of the number of operation repetitions I on the distribution of fatigue damage, results of simulations with 50,100, 150 and 200 operation repetitions were examined (Fig. 2 5).

The means, the standard deviations, and the coefficients of variation for each distribution of fatigue damage are summarized in Table 4. Besides these parameters, Table 4 summarizes the coefficients of skewness $-\beta_{1}$ and the coefficients of kurtosis $-\beta_{2}{ }^{12)}$. Table 4 shows that the standard deviations and the coefficients of variation are not influenced by the number of operation repetitions. However, the parameters $\beta_{1}$ and $\beta_{2}$ became stable after 150 operation repetitions. Then the distribution of fatigue damage of 200 operation repetitions was used to evaluate the distribution of service life.

\section{(3) Service life distribution}

According to the result of this simulation, there were lower and upper limits in the service life of the pavement. Therefore a right skewed Beta distribution was chosen as the probability density function of the service life. On the basis of the relationship between service life and fatigue damage, Fig. 6 was obtained from Fig. 5.

The following equation was obtained from the condition that the statistic $\sum_{i=1}^{k}\left(n_{i}-e_{i}\right)^{2} / e_{i}$ becomes minimum, where $n_{i}$ and $e_{i}$ are the frequencies determined by the simulation and an assumed Beta distribution at the $i$-th increment of service life year. According to Chi-square $\left(\chi^{2}\right)$ test $^{13)}$, the equation is accepted at $5 \%$ of significance level.

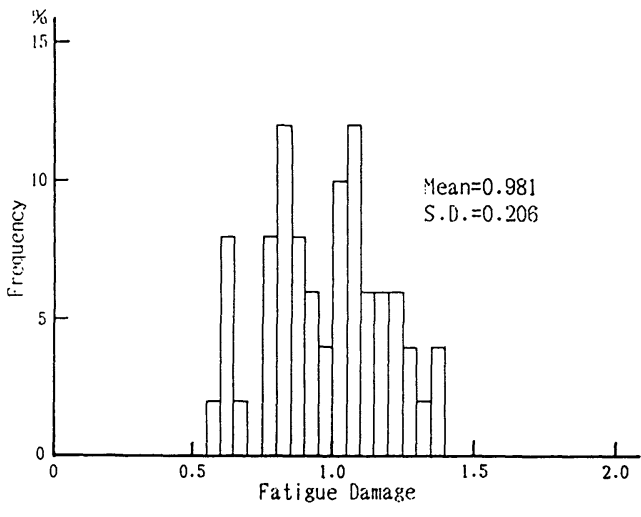

Fig. 250 Operation Repetitions of Simulation.

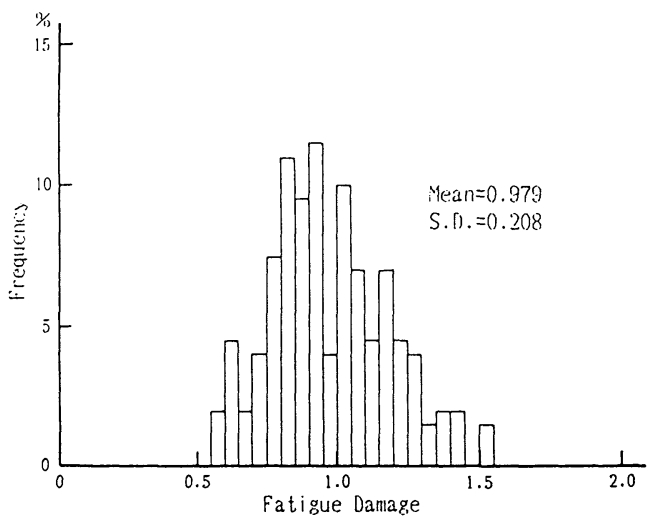

Fig. 4150 Operation Repetitions of Simulation.

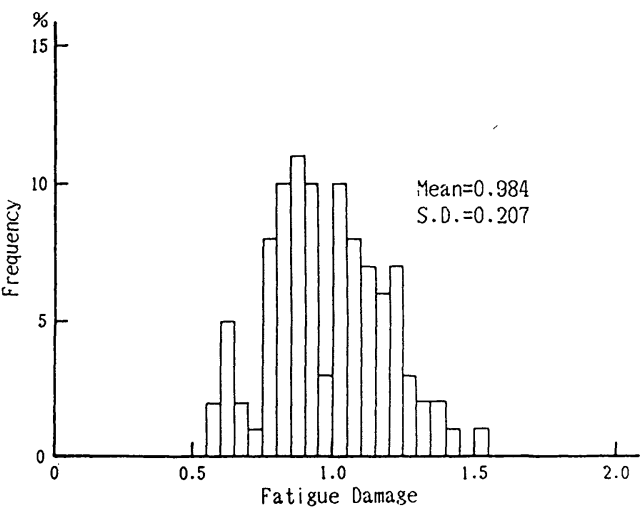

Fig. 3100 Operation Repetitions of Simulation.

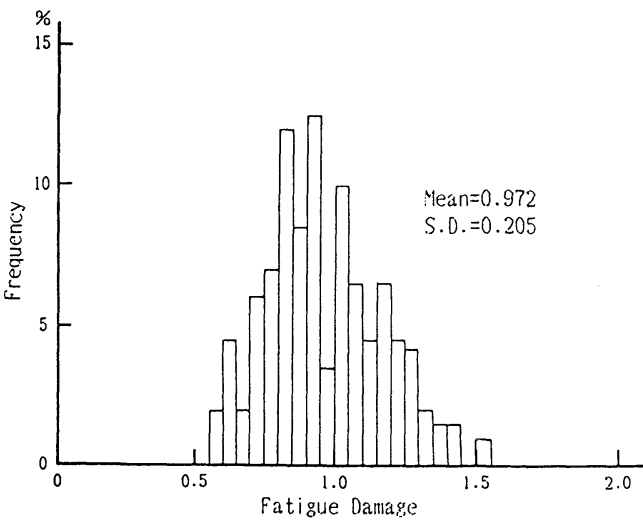

Fig. 5200 Operation Repetitions of Simulation. 
Table 4 Statistics of Simulation.

\begin{tabular}{|c|c|c|c|c|c|}
\hline $\begin{array}{l}\text { Repetitions of } \\
\text { Simulation }\end{array}$ & $\begin{array}{c}\text { Mean } \\
\text { F.D. }\end{array}$ & $\begin{array}{l}\text { Standard } \\
\text { Deviation }\end{array}$ & $\begin{array}{l}\text { Coefficient } \\
\text { of Variation }\end{array}$ & $\beta_{1}$ & $\beta_{2}$ \\
\hline 50 & 0.981 & 0.206 & 0.210 & -0.012 & 2.218 \\
\hline 100 & 0.984 & 0.207 & 0.210 & 0.165 & 2.552 \\
\hline 150 & 0.979 & 0.208 & 0.213 & 0.364 & 2.645 \\
\hline 200 & 0.972 & 0.205 & 0.211 & 0.322 & 2.579 \\
\hline
\end{tabular}

$$
f(\tau)=1.64 \times 10^{-23}(\tau-12)^{2.337}(62-\tau)^{12.077}
$$

where

$\tau:$ service life of concrete pavement expressed in years

According to Eq. (11), the survival probability of concrete pavement within a design life period of 20 years is calculated to be $56.5 \%$, and the confidence interval of design life with a level of significance of $5 \%$ is between 14.5 and 33.0 years.

\section{CONCLUSION}

The purpose of this study is to establish an

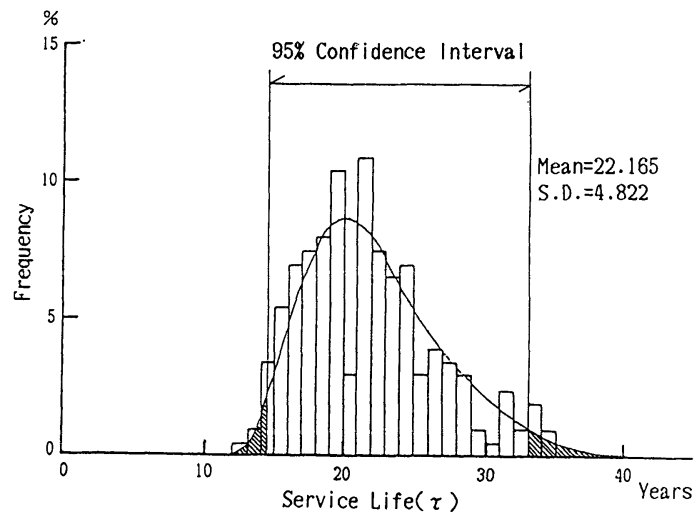

Fig. 6 Service Life Distribution. appropriate method by Monte Carlo simulation to evaluate the service life influenced by the uncertainty factors inherent in concrete pavement.

The following conclusions can be drawn from this study.

(1) Monte Carlo simulation was carried out considering variations of traffic and thermal effects as external factors, and variations of flexural fatigue of concrete as internal factors, since these factors were considered as influential in the estimation of the service life of concrete pavement. The results show that the standard deviation and the coefficient of variation are not influenced by the number of operation repetitions, however, stable results are obtained after 150 operation repetitions.

(2) According to the simulation method described in this study, service life distribution (i. e. density function of survival probability of concrete pavement against time) was expressed by a right skewed Beta distribution. The reliability of concrete pavement can be evaluated by the service life distribution.

In order to design concrete pavement from an economical standpoint, uncertainty factors inherent in concrete pavement should be evaluated. The Monte Carlo simulation can be considered as an effective method for this purpose. In this study, main uncertainty factors in concrete pavement have been considered, however, other uncertainty factors need to be considered in further study.

\section{ACKNOWLEDGEMENT}

The authors are grateful to the graduate students $\mathrm{Ng}$ Kien Chor and Yoichi Shimada for their cooperation in the writing work.

\section{REFERENCES}

1) AASHTO Guide for Design of Pavement Structures, American Association of State Highway and Transportation Officials, 1986.

2) Darter, M. I. : Application of Statistical Methods to the Design of Pavement Systems, Transportation Research Record 575 , pp. 39-55, 1976.

3) Kher, R. K. and Darter, M. I. : Probabilistic Concepts and Their Application to AASHO Interim Guide for Design of Rigid Pavements, Highway Research Record 466, pp. 20-37, 1973.

4) Witczak, M. W. and Johnson, M. : Development of a Probabilistic Rigid Pavement Design Methodology for Military Airfields, Proceedings of Third International Conference on Concrete Pavement Design and Rehabilitation, pp. 167-178, 1985. 
5) Manual for Design and Construction of Concrete Pavement, Japan Road Association, 1984 (in Japanese).

6) Fukuda, T., Koyanagawa, M. and Murai, S. : Condition Survey of Concrete Pavements and Its Evaluation, Proceedings of Third International Conference on Concrete Pavement Design and Rehabilitation, pp. 519-523, 1985.

7) Iijima, H. et al. : Analysis of the Vehicle Weight, Road, No.6, pp. 42-48, 1982 (in Japanese).

8) Shimada, Y., Montaño, J. R. and Koyanagawa, M. : Study on the Effect of Lateral Placement of Wheel, Proceedings of the Annual Conference of the Tohoku Branch of Japan Society of Civil Engineers, pp. 292-293, 1986 (in Japanese).

9) Iwama, S. : Experimental Studies on the Structural Design of Concrete Pavement, Report of the Public Works Research Institute, Ministry of Construction, pp. 1-38, July, 1960.

10) Koyanagawa, M., Kokubu, K. and Fukuda, T. : A Basic Study on the Flexural Fatigue of Concrete Pavement Slab, Proceedings of Japan Society of Civil Engineers, No.372, Vol.5, pp.131-137, 1986 (in Japanese).

11) Rubinstein, R. Y. : Simulation and the Monte Carlo Method, McGraw-Hill, New York, 1969.

12) Harr, M. E. : Mechanics of Particulate Media, McGraw-Hill, 1979.

13) Ang, A. H. S. and Tang, H. W. : Probability Concepts in Engineering Planning and Design, Vol. I, John Wiley \& Sons, 1975. (Received January 19 1988) 